\title{
JACO PRETORIUS
}

Nagraads, Departement Afrikaans-Nederlands

\section{BEWUSSYNSPANNING IN WOORDBEELD: 'DIE WAHLERBRUG' (ELSA JOUBERT)}

\section{Tema}

Hierdie uitsonderlike novelle van Elsa Joubert stem baie ooreen met die prosa van Etienne Leroux, in soverre dit ook die soeke na die self verwoord. Volgens Charles Malan $(1979,17)$ is hierdie reis na binne, die selfontdekkingstog wat die essensie van sy self aan hom moet openbaar, die enigste moontlike avontuur wat vir die moderne skrywer oorbly. In Die Wahlerbrug word dié soektog op grond van die allesoorheersende wet van die principium individuationis gestileer.

\section{Die proses}

Die soektog na die self vind plaas in verskillende fases. Die ongeïndividueerde karakter ontken die bestaan van die onbewuste vlak van die menslike rede of weet nie dat dit bestaan nie. Volgens C.G. Jung is dit egter net so belangrik as die bewuste vlak.

Die ongeïndividueerde ondergaan die bewuswording van die bestaan van die tweede vlak van die werklikheid dikwels deur middel van drome. Die bewuswording van die onbewuste gaan eers gepaard met verset, totdat die brug finaal geslaan word (finale oorgawe), en die ewewig bereik word tussen die bewuste en die onbewuste en die integrasie van die persoonlikheid plaasvind. Om die ewewig te bereik moet alle vaste bewuste grense afgebreek word; daarom is daar in 'n kunswerk soos Die W'ahlerbrug, wat op hierdie teorie gebou is, tydverwarring, (opheffing van die bewuste tyd), ruimteverwarring en identiteitsverwarring.

\section{Die reis na binne}

Die verhaal in Die W'ahlerbrug is 'n reis en 'n ontvoering, maar dit is 'n reis op pad na nêrens - 'n sikliese reis wat begin en eindig by die self, soos die hooffiguur Lottie dit beskryf: "Waar ek ry en ry in 'n bus en nêrens heen gaan nie... Ek is alleen en $e k$ kan die drywer nie sien nie, en van agter kan ek nie lees nie... En dit is donker" (7)*. Hierdie inkering dui op 'n totale

\footnotetext{
- Syfers soos hierdie verwys na Elsa Joubert. 1969. Die Wahlerbruy. Kaapstad, Tafelberg.
} 
desintegrasie van die bekende, 'n beweeg in die donker in, 'n beweeg in die afwesigheid van lig.

Reeds aan die begin van die verhaal is daar ' $n$ distansiëring van die medemens: "Sy skuif nader aan hom... Gieljam het so effens weggeskuif van haar," (7). Die woorde kaats en weerkaats en in die woordspel word die individuasieproses voltrek.

Daar is die voorlopige bespieëling van die self, maar dit vind buite die hoofkarakter plaas naamlik by Lottie se man wat homself spieël: "hy loop na die spieël en betrag sy gesig / terwyl hy nog voor die spieël staan" (5). Lottie daarenteen vind haar sekerheid by ander buite die self, so word 'n onsekere gevoel by haar geneutraliseer deur die "teensinnige warmte" (5) wat hy aan haar verskaf. Die karakter het nog nie sekerheid by die self gevind nie en word telkens deur ander gelei : "Hulle weet wie moet gaan en wanneer en waarnatoe" (5).

'n Toenemende isolasieproses begin homsel! voltrek. Daar is 'n gedurige afspiraling tot die fokuspunt wat in Jungiaanse terme 'n kom tot die self impliseer, hier geskep deur die ruimte: "Die mure en die plafon vernou om hulle tot 'n eindelose tregter, hulle hoor nie die voetstappe nie, want die volvloer-tapyt is dik" (7).

Die ruimtelike inperking gaan gepaard met toenemende stilte. Die isolasie wat plaasvind, is ' $n$ uitsluiting van alles wat buite is en 'n insluiting van alles wat met die self te doen het, dikwels gesimboliseer deur die ander beeld van die bewuste ek wat deur die spieëls weerkaats word: "In die spieëls wat teen al vier kante van die hysbak, selfs teen die binnekant van die deur vasgeplak is, sien sy haar gesig en dié van Gieljam; in die terugkaatsende spieëls wat in die spieëls weerspieël word, word haar gesig en dié van Gieljam eindeloos vermeerder, trek hulle van haar terug in steeds verdwynende, vaagwordende nimbusse klein bekendheid" (7). Die vier kante dui op die volmakkte geslote ruimte.

Die isolasie vernou tot by die hoofkarakter: "Die bus gaan sonder hulle voort. Hulle gaan alleen en apart verder" (8). "'n Klein gevoel van angs groei in Lottie nou dat die tyd gekom het dat sy alleen gaan wees." Dit kan dui op ' $n$ spesifieke tydvak in ' $n$ bepaalde vrou se lewe, 'n oomblik van selfherkenning en selfversoening.

Die hoofkarakter ly aan 'n bewuste sintuiglike onvermoë tot dit wat onder die oppervlakte aanwesig is en al hoe dwingender word in die verloop van die karakter se ontwikkeling, sodat daar eintlik net een moontlikheid is, 
naamlik die oopmaak van die deur wat lei na die binneste.

Die toenemende isolasie gaan gepaard met 'n gerigtheid op die agterkant/ binnekant, as aanduiding van die tweede of onbekende vlak wat bestaan: "Toe die stroom opklaar, het die trein vertrek, (en) sien sy die agterkant van die laaste wa groter en dan kleiner word" (10).

Ook die woordspel dui op 'n vernouing, 'n afspiraal tot 'n fokuspunt, tot niks: "'n Oomblik lank sweef in die leë plek op die spoor waar die trein gestaan het, die beeld van haar gesig soos sy dit in die venster gesien het" (11). Uit die niks word die nuwe selfbeeld gebore.

Die proses wat hom woordeliks voltrek, is 'n stilstand na buite, 'n motoriese stilstand, waarin die hoofkarakter se bewegings beperk bly tot 'n herhaalde loop, eet, slaap, vrugtelose praat, met veral toenemende sit, want uit die stilstand moet die nuwe lewe of beweging kom: "Sy soek'n wegkomkans, gee 'n paar tree na vore en dan terug. Dan staan sy heeltemal stil, verslae"' (18).

Die droomverwysings dui op die feit dat dit ' $n$ reis is in die slaap in, in die donker en onbekende in, wat dikwels geassosieer word met vreesaanjaende beelde.

\section{Die proses word in die woord voltrek}

Die woordspel fokus op twee kernwoorde, naamlik binne en buite. Dikwels word die woorde in dieselfde paragraaf met mekaar gekontrasteer: "Maar in die ingangsaal waar die deure oopstaan na buite, kom die skemerlug en lig van buite na binne en verdring die helder buisverligting. Die koue halfdonker van buite lê op die skouers van dié wat van buite inkom (11). Met die verinnerliking (die beweging van buite na binne) is daar ook' $n$ afname van uiterlike/kunsmatige lig, met 'n groter wordende uiterlike stilstand; daarom: "by die vensters van die kaartjielokette staan" (11). Daarbenewens is daar 'n konfrontasie met 'n geslote deur of venster waardeur nie gesien kan word nie.

Die spieëlbeeld wat in die begin van die verhaal oorheers het, word later vervang deur die glasbeeld, waarin alles ten slotte duidelik moet word. Die glas of spieël wat kan weerkaats, dien as konkretiseringsmiddel van die versperring tussen ' $n$ hierdie kant en 'n ander kant. In aansluiting hierby is daar ook die verwysing na die water, wat ook 'n kant kan weerkaats en soos in die romans van Etienne Leroux ook geassosieer word met die onbewuste, in die vorm van druppels, nattigheid en vogtigheid: "Ook aan die tremdrade wat kruis-dwars oor die straat gespan is, sit klein druppels ingeryg 
soos blink krale" (12). Soos die proses vorder, word Lottie al verder in die onbewuste ingetrek en word sy ten slotte deel van die waterstroom.

\section{Ruimtelike vergestalting van die proses}

Die toespitsing op die self geskied in 'n dikwels vernouende ruimte, in 'n grys toestand (snypunt tussen lig en donker) as die voorstadium tot die nag: "Die strate vernou grys in die verte, en bo haar kop waar die geboue hoog uitsteek vernou dit tot 'n grys streep lug'" (12).

Die verloop van die proses wat hom in die individu voltrek, strek oor'n soeke na identiteit, na die verlies van identiteit, en die aanneem van nuwe identiteit. Die proses verloop soos volg: die bewus wees van 'n naam, die opheffing van 'n naam tot die kom tot 'n nuwe identiteit as geïntegreerde persoon: "Sy lees die name, maar in 'n vreemde taal geskryf, gaan die letters uit haar bewussyn soos sy dit lees" (12).

Die einddoel van die soeke is die bereiking van die volmaakte goud volgens die alchemie, daar is genoeg verwysings na die metaal in die werk: "vergulde paneel" (19); "vergulde barok - soos goud wat drup" (17); "marmertrap" (19). Ook kopernaamplaatjie (12).

Die werk kan dus 'n wyer trefkrag hê as die beperkte tema van die blote identiteitsoeke. 'n Beeld uit die werk versterk hierdie vermoede: "Sy kom op 'n straathoek van waar die fasades van die geboue na vier kante weggeskuif is om 'n oopte of plein te vorm" (12). Paradoksaal suggereer hierdie oopte en museum 'n onverwagte universaliteit.

Dat die proses egter moeisaam verloop, is baie duidelik: "Die ingang is so terloops tussen die ander deure ingedruk, so teenstrydig met die groot struktuur wat sy verwag het, dat sy huiwer om na binne te gaan (13).

Die ruimte is klaarblyklik een van die belangrikste verhaalelemente waarin die individuasieproses duidelik word en waardeur die persoonlike individuasie in die hoofkarakter omlyn word.

\section{Ontplooiing van die proses in die tyd}

Daar kan ' $n$ duidelike prefase in die beelding van die proses onderskei word (5-8). Daar is 'n tydseker voorfases: "Op die tyd", "die program", "dis nou halfagt", "die horlosie", met 'n vooruitwysing na 'n duidelike toekoms gesitueer in 'n tydseker toekomstige tyd naamlik "volgende week". Die tyduitreiking na die toekoms word, namate die werk verloop, verstaan as die 
toestand van tydloosheid, waarná die nuwe tydfase vir Lottie as geïntegreerde persoon sal aanbreek. Aan die einde van pagina drie word die tyd verskuif na die oomblik, die ruimte, tot die situasie. Daar kom 'n stilstand voor die deur en daar word begin met die betreding van die deur na die ander kant, in toenemende stilte in afnemende lig en met verlies van identifikasie: "Die deur, toegemaak teen die koue, gee geluidloos mee... 'nflou, outydse gelerige gloeilampie... maar nie om die mense onmiddellik agter te kom en te identifiseer nie" (13).

Soos die ruimte, word die uitbreiding op die tyd gedoen in samehang met die karakterontplooiing.

\section{Karakterontwikkeling}

Om die individuasie te laat plaasvind moet daar 'n ongeïndividueerde hoofkarakter wees. Die hoofkarakter Lottie Holme word gekonfronteer met die volmaakte eenheid van die onbewuste, gesimboliseer deur die viertal “binnekarakters" naamlik: 'n vrou, 'n meisie, 'n ou man en 'n jong man. Die karakters van buite (bewuste), word vervang deur die "binne-karakters" (onbewuste), met 'n groeiende onvermoë van die hoofkarakter om die buitemense te bereik.

Die binne-karakters eis van Lottie alles wat sy as bewuste weerstand besit, gesimboliseer deur haar jas en ook haar handsak: "sy voel die meisie aan die skouers van haar jas vasgryp, met 'n geoefende beweging dit van haar rug en arms stroop" (14). Sy' word gestroop van alles wat sy as skans kan gebruik, sy word oopgestel vir die proses om homself in haar te voltrek.

Die eerste fase word afgesluit met die ouer man as begeleier van Lottie deur die "dubbele deur" (14), waardeur sy gaan. Met ander woorde'n tweede of verder stap agter die deur in.

In die volgende stap word die fokus verplaas van die deur na die venster: "Glasvensters wat tot kniehoogte sak, is ondeurskynend, maar laat 'n dowwe lig soos dié van flou elektrisiteit deur" (14). Die venster moet dit wat versluier of duister is, oopmaak. Tog is die visie tot op hede beperk, alhoewel die assosiasie met dit wat agter die vensters is, voelbaar vergestalt word deur die beskrywing van die beelde wat voor die vensters staan, naamlik "borsbeelde (halwe beelde - J.P.) op swart granietstaanders" (14).

Die proses van vervreemding - verlies van identiteit of die voorbereidende aflegging van die vooropgestelde eise wat die rasionele mens aan alls stel word deur Lottie ervaar: "(Sy) probeer die lewe soos sy dit ken, in hierdie 
kamers indwing. Maar dit is onmoontlik" (15).

Dat die hoofkarakter besig is om self innerlik te groei, word weerspieël deur haar denke wat oorspoel word deur die onbewuste wat dreig om deur die oppervlakte te breek, soos geel, waterige lig deur glas: "Die lig is nie van die wèreld buitekant nie, maar kom van 'n binnehof... Vaagweg is sy daarvan bewus... met 'n gevoel wat na die onbegrypiike begrip - die verlede -uitreik" (16). Hierdie bewuswording gaan gepaard met die uit wissing van bewussynsgrense van tyd en ruimte en persoon, dit is 'n vervloei of desintegrasie om sodoende te kom tot die volle eenheid, en dit word gesuggereer deur die houding van die man (beeld van die ander ek) wat haar agtervolg: "Hy staan by die venster waardeur hy nie kan sien nie, hy kyk -na niks" (17).

Die hootka rakter word egter nog bevrees deur die oorgee an die proses wat in die omgewing rondom haar gestalte vind, om haar sodoende te dwing tot insig en selfkennis: "Sy het die kamers agtergelaat, staan in 'n vestibule. Die plafon reik bo haar weg, voor haar'n wenteltrap van marmer met swaar wit naaktc vrouefigure wat soos pilare die draai van die trap afmeet" (17). Die aandrang van die oomblik en beeld van die ander-ek word al dringender: "Sy sien sy beeld in die spieëls nader kom/... dat sy weer bewus word van hom" (17).

Hierdie fase wat ook hoofstuk een afsluit, eindig met die magtelose verset: "Sy het nou 'n doodloopstraat gekies. Die groot oopgeslane voudeure van die laaste kamer staan roerloos, wyd oopgesprei, bied haar 'n stom uitdaging om binne te gaan"; sy gaan oor na die ander kant deur die muurpaneel.

Die teenstanders is uitbeeldings van die ander-ek, die skadu, die anima en animus, en ook die verenigde konfrontasie van die onbewuste. Dit blyk byvoorbeeld uit die volgende: "Daar kom 'n man uit die skaduwees na vore" (20), wat ooreenkoms toon met haar wettige man, sy gebruik dieselfde beskrywende woord vir albei: "nerveuse skouerbeweging" (20), wat ook voorheen (pagina 6) vir die beskrywing van haar man gebruik is. Haar man was haar begeleier op reële vlak, en nou is die taak oorgeneem deur Schwarz; albei lei haar tot in 'n oomblik wanneer sy aan haarself oorgelaat word.

In hoofstuk twee het die proses al verder gevorder: "Sy wil die werklikheid waaraan sy gewoond is, na haar terugdwing" (21), maar slaag nie daarin nie. Sy word uit die tyd verhef: "Dis asof sy opnuut die treinbord in die stasie sien waarop die tye van die vertrek van treine en hulle bestemmings in ligte uitgespel is, en dan soos die tyd verloop, uitdoof' (24). Die proses, alhoewel sy dit nou bewusteliker besef, is nog nie voltrek nie: "(dis) of sy êrens 'n venster kan sien of die lug (daar) buite... die donker lê buite die lig" (24). 
Die ruimte vernou algaande tot clie al: zenheid van die binnekant - 'n voorlopige saamwees met die self: ' Die c'sur word agter haar toegeklap, dit is stikdonker binnekant. Sy is alleen in d. donkerte" (25); tog probeer sy haar nog verset, maar daar is ook alreed. $d i$. poging om die onbewuste met die bewuste te versoen "haar hande $\mathbf{c} \mathbf{m}$ cie rand van die bankie onder langs haar knieë vasgeklem om ewewig te b:hou" (26). Uit die verkryging van ewewig kom die insig, besef, en moor, 'tke versoening: "Die swart het soos skuiwende mure om haar ingeskuif, in die swart het... die punt van haar bewussyn 'n skerpte geword wat dieper in die duisternis wegsak"' (26).

Die oomblik van opligting is egter nog nie bereik nie: sy verset haar nog, maar dat dit 'n tydelike verset is, blyk uit die volgende: "sy stamp met haar vuiste teen die swart kleedstof, maar die beweging word klammerig opgesuig. Haar stamp is meer 'n liefkosing as verset" (29).

Die bewegings wat uitgevoer word, bevestig die dubbelkantigheid van die situasie waarin die hoofkarakter haar bevind. Dit is 'n herhaalde in- en uitbeweeg wat namate die verhaal vorder, altyd weer eindig by die terugkeer na binne. Die proses raak moeisamer; die hoofkarakter moet steun op die hulp van een van die binnekarakters: "Toe die vragmotor stilhou, klim sy moeisaam uit ... Daar is nie 'n plank reggesit vir haar om op uit te loop nie... Dit is ' $n$ inspanning. Schwarz help haar aan die arm. Hulle het nie op straat stilgehou nie, maar ingedraai by 'n gebou, ingetrek in 'n soort binnehof" (29 en 30).

Daar is die terugkerende afspiraling sodat die fokus val op 'n ruimtelike binnehof, wat later die binnehof van die persoon self word - 'n trapsgewyse proses: "Die agterkante van die huise wat in 'n kring gebou is, loop met trappe af na die binnehof" (29). Teenoor die opgerigte "beskawingskanse" wat opgebou is, staan die verset van die onbewuste (meer primitiewe), in die aanhoudende aanwesigheid van "onbekende magte" wat 'n teenproses uitvoer, woordeliks vergestalt in die woord af: "Die huise is nie van klip gebou nie, maar geel gekalk en waar die geute lek, drup die roesmerke af (30).

Die besef van die proses is anwesig by Lottie, maar die kommunikasiemiddel ontbreek nog. Die gewaarwording moet nog woordgestalte vind. Die proses kan dan ook in verband met die soeke na die volmaakte kunstenaarskap gebring word - naamlik die bereiking van die diepste bron of inspirasie wat in die nuwe prosa gelyk is aan die innerlike reis en die woordgestalte daarvan. Die titel is ook'n aanduiding hiervan; 'n brug moet geslaan word, en dit moet ook in die taal geslaan word. Aan die begin is dit die taalprobleem waarteen die hoofkarakter stuit. Namate die verhaal vorder, verdwyn die geluid (taal) en in die plek van die taal kom die teken, 
wat die taal van die onbewuste versimboliseer: hierdie teken moet ten slotte weer taal word, dit wil sê daar moet talige kommunikasie wees tussen die twee vlakke: "Op 'n teken van die hoofportier gly 'n taxi nader" (9); "Die kelner met sy skinkbord is 'n universele teken" (10).

Tesame met die ruimtelike en personale inperking kom sy al meer tot die fokuspunt: "Sy sit in haarself in gehurk" (31). Tog is dit ook nog nie die finale inbeweeg nie, soos dit woordelik gebeeld word: "Dis'n vangriem van geluid, maar dit krul nie terug nie, dit vloei uit" (31).

Sy raak wel losser van die bekende dinge: "Dis asof haar oë afskeid neem van die geldsakkie wat Schwarz in sy sak gestop het, nie omdat sy dit wil behou nie, maar omdat dit al is wat sy ken; asof sy die handsak wat hy haar wil gee, nie begryp nie" (32). Die besef dat sy iets moet prysgee alvorens die brug geslaan word, is daar, maar die begrip ontbreek nog.

\subsection{Voorlopige insig}

In hoofstuk drie begin die lig in die venster weerkaats, 'n na-binne-lig: "Die donker het soos met 'n lap die beeld van buite wat teen die venster vasgeplak was, weggevee. In die glas van die venster is die warmte van die verwarmer wat voor Schwarz se voete brand 'n klein rooi gloed" (34).

In hierdie hoofstuk is daar ook die eerste daadwerklike stap in die aflegging van die personale eensydigheid. Sy word deel van die ander kant; daar is 'n opheffing van identiteit, 'n wegbeweeg van die bekende, beperkende na die ontdekking van die totale self: "Sy het die knope voor toegeknoop tot by haar hals, asof sy haarself of die self in die ander vrou se jas vir Schwarz wou verberg" (35).

Schwarz is die begeleier van haar die nag in, maar net tot op 'n sekere punt; daarna lê die keuse by haarself en moet sy self weer kom tot by die Wahlerbrug: "Dis by die Wahlerbrug dat ek woon, die trein- en motorbrug, as jy my soek, hoor. Toe het sy arm die deur agter haar toegeklap, swaai hy die wiel om om weer in die stroom van die verkeer opgeneem te word" (36). Dit is seker een van die beste omlynings van Lottie as buitestaandersfiguur.

Lottie het al begrip vir haar taak, maar soek die oplossing steeds buite haarself en die antwoord kan sy nie daar vind nie: "Ek moet met iemand praat wat alleen is... nie my taal nie" (38). Sy word dus tot haarself gedwing deur

1. die teenkarakters: "Sy rug is vir haar gekeer" (39);

2. die ruimte: "Die spieèls aan die mure, slank en waardig, weerkaats die donkerte" (39); 
3. die tydsverwarring: "Ons het vertrek, maar ek wil weer inteken... Vanoggend? Ons is die aandstaf" (39);

4. die taal: "Kom gee, vroetel die hand na haar, praat die vingers in onbegrensde taal, vroetel dit tot haar bewussyn deur" (42).

Sy word uitgestoot in die lig, in die reële, die werklikheid, om daar tot die volmaakte versoening te kom, maar sy is op hierdie stadium nog nie daartoe in staat nie, en dit word aangedui deur die onvermoë om die kofferkleur te onderskei: "Hoe sien sy dan soveel gryses... hoe speel haar oë haar so parte" (44). Grys is die oplossingspunt van wit en swart as die twee kleure van die bewuste en die onbewuste. Die grysheid kan ook dui op haar groeiende identiteitloosheid, die oplos van die individu, die uitwissing van grense waarteen 'n brug geslaan moet word: "Ek weet nie watter is myne nie. Ons het hulle nuut gekoop, daar is so baie en so eenders" (44).

As haar beperkende eie identiteit oplos, verkry sy insig, 'n deursien deur die venster; deur die innerlike versoening kom die beeld van die buite-wêreld ook in die regte perspektief, 'n aanduiding dat die proses al ver verloop het, maar nogtans nie voltooi is nie: "Deur die glas aangeklam van die stoom... sien sy bewegende figure van mense wat eet en drink" (45), "sy sien haarself en Gieljam wat dit doen. Maar nou is sy buite die glasversperring" (46).

$\mathrm{Na}$ hierdie geopende perspektief beweeg sy verby die versperrings, beweeg sy vanself uit: "gaan sy by die groot glasdeur van die stasiewagkamer uit" (47), en die resultaat is die terugkeer en die oorgee aan die onbewuste, versimboliseer deur die slaap: "Dit was asof sy slaap van maande inhaal, asof daar nou vir die onsekere gespanne slaap van die hele reis vergoed moet word" (47).

Die oomblik dat die bewuste terugkeer, ontken sy die proses wat besig is om in haar voltrek te word: "Daar het gister eienaardige dinge met my gebeur. Maar ek kan dit te bowe kom. Ek het nog my verstand en kan nog my woord doen... Ek is tog nog ek" (48).../"Maar sy't nog altyd haar houding. In 'n vreemde jas of nie" (49). Tog is sy alreeds geklee in die jas met die "bruin en wit geruite patroon" (48) - simbool van die oorgang van die bewuste (wit) na die onbewuste (bruin, amper swart), wat tans balanseer.

In die konflik met die twee jong meisies van die lugrederykantoor verloor sy haar denke: "Haar gedagtes tuimel heen en weer, haar brein, haar denkvermoë, wil-wil in rat kom, dit ruk na vore, word gestuit, sy kan nie dink nie... die vaagheid van haar begrip van die situasie" (52).

Daar kom byna die oomblik van opligting: "Dis asof daar hulpvaardigheid 
wil kom, by die oppervlakte van die meisie wil deurbreek, voel sy dit aan" (53). Dit is 'n voorlopige klimaks: "Verskrik oor die oomblik van byna verwikkeld raak met die byna-aanraking van die hande aan haar, het die meisie teruggetrek" (53). Sy bly op die oppervlakte en kan nog nie deurbreek nie; dit word dan ook woordeliks gebeeld: "Aan die straatoppervlaktes kleef die nattigheid bo-op vas... een van die druppels val op die gesig van Lottie" (54); so word sy stelselmatig deel van dit wat tot dieper as die oppervlakte kan deurdring.

Hierdie klimaks word voortgesit tot die konfrontasie met die selfbeeld in 'n oomblik van selfopenbaring, al kan die besef nog nie in die bewuste aanvaar word nie: "Al herken ek nie die beeld nie, dit is nog ek wat dit beweeg" (55). En verder af: "Die tweede beeld wat sy is, loop in die winkelvenster saam met haar". Dit is die openbaring van die negatiewe ander-ek wat elke mens met sy selfbeeld wat hy vir homself bewustelik positief voorhou, moet versoen. Die afwisseling tussen ek-en sy-perspektief dui op die objektiewe selfbeskouing.

\subsection{Die versoening}

$\mathrm{Na}$ die openbaring moet die versoening plaasvind, 'n nuwe begin moet gemaak word, 'n lewenspad moet nou bewandel word waarin albei kante in ewewig gehou word: "Ek moet begin waar ek toe begin het, ek moet die pad terugloop" (56). Daardeur kom die helderheid, die opklaring: "Die pad vurk oop - die wit water van die fontein stort oop" (56). Die onversoenbare is nou met mekaar versoen. Wit was tot nou toe geassosieer met die bewuste (paginas 27, 48, 49), en die water met die onbewuste (paginas $26,36,37$ ), en nou word hulle as een begrip versoen.

$\mathrm{Na}$ hierdie oomblik is daar nie meer keer nie: "En toe sy deur is, kan sy nie terugdraai nie..." (57), en kom die moontlikheid om deur te breek in die taal na vore: "Dis my kans, dink sy, want die gids praat beurtelings die taal wat sy verstaan en die vreemde taal" (58).

In die polisiekantoor begin sy die nuwe pad loop, die pad terug na waar alles begin het, na die oeroorsprong, en dit impliseer' $n$ terugkeer in die tyd: "Sy word teruggedruk in die tyd... hulle krabbel terug in die tyd... Sy probeer uit die verlede wat nou in 'n verre dimensie in mekaarloop soos kleure wanneer water daarop val, 'n sentrale punt haal waaraan sy die raamwerk van haar lewe kan heg" (61 en 62).

Die verlede word in taal vergestalt; dit word ' $n$ openbaring van alles wat al vergeet is, 'n swart op wit bring van die verlede: "Sy skryf hulle name neer, 
in drukletters netjies meer leesbaar as iets wat nog in die vorm verskyn het" (62). "Noudat haar lewe of nielewe op die papier neergeskrywe staan, swart op wit" (63), herken sy die twee vlakke van bewuste en onbewuste, daarom trek sy die werklike name dood en gee aan haar kinders fiktiewe name. Dit val binne die hele dupliseringsproses in die werk, naamlik die verloor van reële identiteit ter wille van volle identiteit (geïntegreerde persoonlikheid), en daarvoor moet sy uit die reële tyd verlos word; daar is dus 'n opheffing van die bewuste tyd om sodoende die tyd-ophefling van die onbewuste te kan ervaar. Dit vind plaas in Lottie deur in te beweeg in die verlede en uit te beweeg uit die hede; die reële tyd word opgehef.

Nadat die tydsperspektief na die verlede verskuif het, ontdek sy die tweede kant van die werklikheid, en het sy na haar voorlopige insig "regte mense" ontdek (36), maar na die geopende visie ontdek sy ook ou mense en die negatiewe menslike element soos prostitute (46), lammes en die blindes en die ou man (65). Die volle aanslag van die werklikheid breek die laaste skans wat haar terugkeer moontlik maak - "Sy het nie meer haar houding nie, want haar skouers het gesak, haar maag bult uit soos dié vrouens s'n" (65). Sy keer dan ook terug na die Wahlerbrug met haar nuwe insig en kennis: "Die armuedige sirkel huise, die grondbinneplaas... Sy weet watter trap om op te gaan", 66).

In hoofstuk vyf volg die finale oorgawe, die terugkeer tot die versoende self, met Schwarz as begeleier. Dan is sy bewus van die oorgawe, maar dit is nog voorlopig 'n halwe oorgawe wat deur die halfbeelde gedra word: "die glas was halfleeg uitgedrink is" (67), "deur die ooglid-versluierde oë" (69), "halfhuiwerig" (69). Die kontak is nog half.

Schwarz lei haar uit na die finale konfrontasie: "Die buitetrap wat sy nou saam met hom afloop, is bekend, vertroud" (72). Hy lei haar na die hotel waar sy gekonfronteer word met die volle eenheid van die vier binnekarakters naamlik die ouvrou, die jong meisie, die ouman, en die jong man. In haar hotelbed kom die versoening van die lig van die duister en die lig van die dag wanneer sy weer slaap; dit wil sê in die toestand van eerlike verkeer met die self: "Later toe dit begin lig word, het die lig van die gloeilampie saamgevloei met die lig van die dag totdat die twee nie meer onderskei kon word nie" (75). Op daardie oomblik ervaar sy die twee vlakke, maar sy is nie in staat om daaraan taalgestalte te gee nie: "Sy kon nic sê op watter vervlietende oomblik is hulle nuu vasgevang nie. Net iets het sy herken... so onbereikbaar, so onbegryplik" (76 en 77). Reeds ervaar sy die vreemde gevoel van dit wat aan haar on bekend is: "Dit het vir haar vreemd gevoel... tog het dit vir haar gevoel dat dit by die klere pas" (77). Maar sy kan nog nie ten volle begryp nie: "Soos 'n vervlietende beeld nie in bewegende water 
vasgegryp kan word nie, so kon sy nie haar eie beeld vasgryp nie... nie deut woord of reaksie nie" (77). Dit word naas die personale problematiek van die hoofkarakter ook 'n skrywerskapproblematiek: "Ek weet nie wat om te skryf nie. Of aan wie nie" (80).

Die proses het al so ver gevorder dat sy nou vanself die aksie uitvoer, vanuit haarself: "Dié keer is dit hy wat klop en sy wat oopmaak" (81), en kan sy selfs al die nie-reële as werklikheid ervaar: "Sy sien die fyn ongelykheid in die pleistering van die mure wat straal van lig, sy sien die ronding in die swaar gordyne, vol van vervulling, sy sien in die hout die grein groei" (83).

Waar sy vroeër (36) regte mense ontdek het, dit wil sê die selfstandig rasionele mense, en later ook die negatiewe menslike element (56), ontdek sy nou ook die nie-reële mens: "Sy het aan die onsigbare mense gevra... om hulle beelde uit die spieëls vir haar terug te gee" (86). Dit dui op die tweevlakkigheid van die menslike bestaan wat in elke individu met mekaar versoen moet word; daarom vind sy ook nie die antwoord elders as by haarself nie: "Sy het nie 'n geluid gehoor behalwe haarself nie" (86). Dit is die besef van alleenheid in sy volheid waarin die proses hom finaal kan voltrek: "Ek is alleen, sê sy" (87). Hierdie besef of insig breek deur na die oppervlakte, en Lottie en die ou man verstaan mekaar: "Hoe verstaan ek jou nou?... praat ek jou taal of praat jy myne?" (87).

Hierna volg die volkome oorgawe aan hom wat die nie-reële verteenwoordig: "Sy het teruggeleun, oorgegee aan hom soos 'n kind" (88).

Die waterbeelde het nou tot voltooiing gegroei - van "effens waterig" (88) tot "vol water" (89), en dit omsluit en deurdring vir Lottie: "Die stoom begin klam en warm om haar bene opstyg" (90). In die vorm van koffie drink sy dit as "warm swart soet vloeistof". Hierna, in die klimaks van die identiteitsdesintegrasie, word sy finaal gekonfronteer met haarself of haar ander-ek as sy soos die ou man haar oë inspan om in die ontvangsboek op die hoteltoonbank te kyk: "Hy lees haar naam. Lottie Holme. Dit was sy, sê hy. Hy vat met bewerige vingers aan die mou van die klere wat sy dra. Sy" (9l).

$\mathrm{Na}$ die finale oplossing of antitese moet die sintese weer gevind word, 'n terugkeer tot die normale bestaan. Daarom begin Lottie die wanorde wat sy in die kamers aangerig het, te orden voor die finale konfrontasie met die ander-ek, wat gestalte vind in die ander vrou: "Ek weet jy sou kom... ek dink ek het van die eerste dag af geweet. Of baie vroeër... dat jy sou kom" (93).

In hierdie laaste konfrontasie vind die versoening en die aanvaarding plaas: "Soos wanneer twee vrouens na mekaar kyk, is daar die eienaardige 
spanningsloosheid, afsydigheid maar ook betrokkenheid, sonder spanning. Van nie twee pole te wees nie, maar op een vlak. 'n Aanvaarding. 'n Bloot wees, met die voorbehoude dat ander elemente nie bygebring word nie" (94).

Die slotgedeelte word voltooiing van die siklus, eers moes sy van buite beweeg en nou dat die sintese plaasgevind het, moet sy weer na buite beweeg: "Op haar tone uit geglip... het sy die wenteltrap afgegaan ... ek gaan uit" (96). Sy neem weer haar reële beeld aan: "Maar dit wás haar jas, die eerste jas" (98). Die reële self neem nou willekeurig die tog in die donker in: "Sy het in die donker uitgeloop" (98). Sy het die geïntegreerde toestand bereik sodat sy die twee vlakke gemaklik met mekaar kan verwissel: "So het sy uit die een ligkol na die donkerte, van die donkerte na die volgende ligkol geloop" (98), totdat sy vanself tot die diepste wese kon deurdring: "voel-voel oor die eerste kliptrap, begin afklim... (later) het sy met meer sekerheid geloop totdat sy by die rivieroewer was (99).

Nou keer die herhaalde waterbeelde terug - 'n proses in die kleine word ook voltooi; eers loop die water aan haar sy: "Die water het in 'n donker vloed langs haar voete verby geloop" (99). Sy word al hoe verder deel van die water (onbewuste): "Druppels vorm op haar hare van die klammigheid... sy het langs die donker oewer van die stroom gelonp, met die vloei van die stroom saam" (99). Deurdat sy deel word van die stroom (simbolies) kan sy die brug slaan, kan sy dinge onderskei (99). Schwarz as haar begeleier is nou oorbodig, sy is nou self in staat om die pad alleen te loop.

Die Wahlerbrug blyk dus 'n toonbeeld te wees van hoe woordtegniek woordkuns word. Asof in 'n spieëlbeeld word die tema van die soeke na die self in elke dominante woord weerspieël. In die patroonmatige en noodwendige gebruik van die eenvoudige woord, meestal die simpleks, herken 'n mens die hand van die skryfster van die kortwerk in die latere bundel Melk.

\section{BRONNE}

JUNG, G.C. 1948. The integration of the personality. JUNG, G.C. 1964. Man and his symbols. London. W.H. Allen. MALAN, C.W. 1978. Misterie van die alchemis. Kaapstad, Academica. 